\title{
Article \\ Synthesis of Caffeoyl-Prolyl-Histidyl-Xaa Derivatives and Evaluation of Their Activities and Stability upon Long-Term Storage
}

\author{
Hyeri Jeong ${ }^{1,+}$, Young-Eun Jeon ${ }^{1,+}{ }^{\mathbb{D}}$, Jin-Kyoung Yang ${ }^{2}$, Jaehi Kim ${ }^{2}$, Woo-Jae Chung ${ }^{3}$,, Yoon-Sik Lee ${ }^{2,4}, *$ \\ and Dong-Sik Shin $1,5, *$ (D)
}

1 Department of Chemical and Biological Engineering, Sookmyung Women's University, Seoul 04310, Korea; wpg@sookmyung.ac.kr (H.J.); jun24600@sookmyung.ac.kr (Y.-E.J.)

2 School of Chemical and Biological Engineering, Seoul National University, Seoul 08826, Korea; yjk0627@snu.ac.kr (J.-K.Y.); susia45@snu.ac.kr (J.K.)

3 Department of Integrative Biotechnology, Sungkyunkwan University, Suwon 16419, Korea; wjchung@skku.edu

4 BeadTech Inc., 10-dong 4th, 49 Wonsi-ro, Danwon-gu, Ansan-si 15610, Korea

5 Industry Collaboration Center, Sookmyung Women's University, Seoul 04310, Korea

* Correspondence: yslee@beadtech.co.kr (Y.-S.L.); dshin@sookmyung.ac.kr (D.-S.S.); Tel.: +82-31-8084-8359 (Y.-S.L.); +82-2-2077-7236 (D.-S.S.)

+ These authors contributed equally to the work.

\section{check for} updates

Citation: Jeong, H.; Jeon, Y.-E.; Yang, J.-K.; Kim, J.; Chung, W.-J.; Lee, Y.-S.; Shin, D.-S. Synthesis of Caffeoyl-Prolyl-Histidyl-Xaa Derivatives and Evaluation of Their Activities and Stability upon Long-Term Storage. Int. J. Mol. Sci. 2021, 22, 6301. https://doi.org/ $10.3390 /$ ijms 22126301

Academic Editor: Maria

Luisa Balestrieri

Received: 21 May 2021

Accepted: 7 June 2021

Published: 11 June 2021

Publisher's Note: MDPI stays neutral with regard to jurisdictional claims in published maps and institutional affiliations.

Copyright: (c) 2021 by the authors. Licensee MDPI, Basel, Switzerland. This article is an open access article distributed under the terms and conditions of the Creative Commons Attribution (CC BY) license (https:// creativecommons.org/licenses/by/ $4.0 /)$.

\begin{abstract}
Antioxidants play a critical role in the treatment of degenerative diseases and delaying the aging of dermal tissue. Caffeic acid (CA) is a representative example of the antioxidants found in plants. However, CA is unsuitable for long-term storage because of its poor stability under ambient conditions. Caffeoyl-Pro-His- $\mathrm{NH}_{2}$ (CA-Pro-His- $\left.\mathrm{NH}_{2}, \mathrm{CA}-\mathrm{PH}\right)$ exhibits the highest antioxidant activity, free radical scavenging and lipid peroxidation inhibition activity among the histidinecontaining CA-conjugated dipeptides reported to date. The addition of short peptides to CA, such as Pro-His, is assumed to synergistically enhance its antioxidative activity. In this study, several caffeoyl-prolyl-histidyl-Xaa- $\mathrm{NH}_{2}$ derivatives were synthesized and their antioxidative activities evaluated. CA-Pro-His-Asn- $\mathrm{NH}_{2}$ showed enhanced antioxidative activity and higher structural stability than CA-PH, even after long-term storage. CA-Pro-His-Asn- $\mathrm{NH}_{2}$ was stable for 3 months, its stability being evaluated by observing the changes in its NMR spectra. Moreover, the solid-phase synthetic strategy used to prepare these CA-Pro-His- $\mathrm{Xaa}-\mathrm{NH}_{2}$ derivatives was optimized for largescale production. We envision that CA-Pro-His-Xaa- $\mathrm{NH}_{2}$ derivatives can be used as potent dermal therapeutic agents and useful cosmetic ingredients.
\end{abstract}

Keywords: solid-phase synthesis; caffeic acid; caffeoyl peptide derivatives; antioxidant; stability

\section{Introduction}

Reactive oxygen species (ROS) include highly reactive free radicals, such as peroxide (ROO') and superoxide $\left(\mathrm{O}_{2}{ }^{\circ}\right)$. ROS induce oxidative stress in the human body via radical chain reactions, thereby causing damage to DNA or RNA, cancer, chronic disease and aging $[1,2]$. In addition, oxidative stress can cause degenerative diseases such as Alzheimer's disease [3-5].

Natural antioxidants found in various foods, including vegetables, meat, fruits and grains, inhibit the activity of ROS. They are considered suitable agents for scavenging radicals but are unsuitable for practical use as antioxidative nutrients or therapeutic agents because of their low concentration and/or activity [6,7]. Therefore, many synthetic antioxidants have been studied to prevent food corruption, delay the aging process, and treat degenerative diseases via scavenging ROS [8-11]. However, there are restrictions on the use of synthetic antioxidants, such as tertiary butylhydroquinone (TBHQ), butylated 
hydroxyanisole (BHA), butylated hydroxytoluene (BHT) and bisphenol (BP), because they are potentially cytotoxic when used in high concentrations [12].

Phenolic compounds have been extensively studied as antioxidants because they provide a relatively stable free-radical structure after losing a hydrogen atom. Previous reports have shown that the antioxidant activity of phenolic compounds increases upon increasing the number of hydroxyl and methoxy groups on the phenyl ring [13]. Caffeic acid (CA, 3,4-dihydroxycinnamic acid) is a member of the hydroxycinnamic acid (HCA) family and is often found in nature. CA exhibits high antioxidant activity because of the delocalization of non-covalent electrons in its extended side chain [14]. In addition, the ortho-dihydroxyl group in CA forms a stable hydrogen bond after dissociation of the $\mathrm{O}-\mathrm{H}$ bond [15-17]. To date, various CA derivatives, such as CA-triazole, CA-tyramine and CAamino phenol, have been studied. However, such CA derivatives have insufficient redoxactive catechol moiety or participate in side reactions, which decrease the antioxidative activity [18-20].

We have previously reported that the conjugation of CA to a peptide can enhance its stability. In particular, CA-Pro-His- $\mathrm{NH}_{2}$ exhibits the highest antioxidant activity reported to date because the s-cis proline conformer contributes to the increased antioxidant activity of CA (Figure 1) [21-26]. In this study, we expected that some of the CA-tripeptide derivatives would exhibit better antioxidant activity and stability than CA-Pro-His- $\mathrm{NH}_{2}$. Therefore, several CA-Pro-His-Xaa- $\mathrm{NH}_{2}$ derivatives were synthesized as an extended library from CAPro-His- $\mathrm{NH}_{2}$, and their antioxidant activity and long-term storage stability were evaluated.
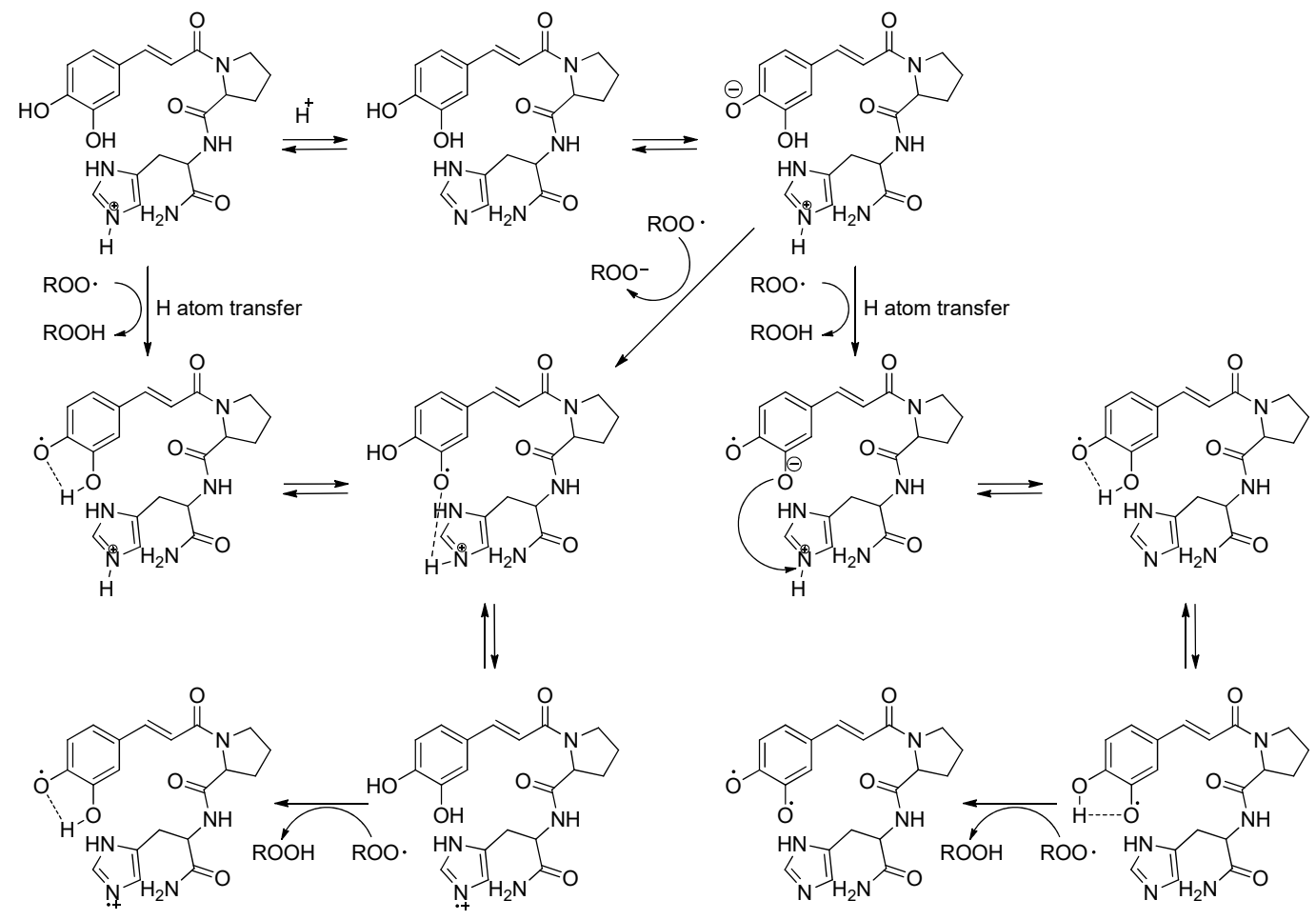

Figure 1. Antioxidant mechanism of CA-PH- $\mathrm{NH}_{2}$ with peroxyl radicals based on an $\mathrm{H}$-atom transfer and single-electron transfer mechanism. Reproduced from [26], with permission of Springer Nature Limited.

\section{Results and Discussion}

\subsection{Synthesis of $\mathrm{CA}-\mathrm{PHX}-\mathrm{NH}_{2}$}

Several CA-PHX- $\mathrm{NH}_{2}$ derivatives were synthesized on Rink amide aminomethyl polystyrene (AM PS) resin using Fmoc-chemistry-based solid-phase peptide synthesis (SPPS) (Scheme 1). Prior to coupling CA to the peptides on the resin, the purity of the $\mathrm{PHX}-\mathrm{NH}_{2}$ synthesized on the resin was determined using high-performance liquid chro- 
matography (HPLC) after a small-scale cleavage reaction. The HPLC analysis showed that the purity of PHX-NH $\mathrm{NH}_{2}$ synthesized using Rink amide AM PS resin was $>93 \%$. The effect of the resin on the purity of $\mathrm{PHX}-\mathrm{NH}_{2}$ was evaluated by synthesizing $\mathrm{PHX}-\mathrm{NH}_{2}$ using Rink amide 4-methylbenzhydrylamine (MBHA) resin, which is known to result in higher purity during SPPS [27]. Unexpectedly, the Rink amide AM PS resin gave an approximately two-fold higher yield than Rink amide MBHA resin, as well as a 3-7\% higher crude purity for all the compounds studied (Table 1). The Rink amide MBHA resin released the fragment of Rink amide linker as well as the tripeptide products during the final cleavage step, whereas Rink amide AM PS did not release any compound except the tripeptide products. This affected the purity and yield of the tripeptide products observed during HPLC when the peptides were synthesized on Rink amide MBHA resin.

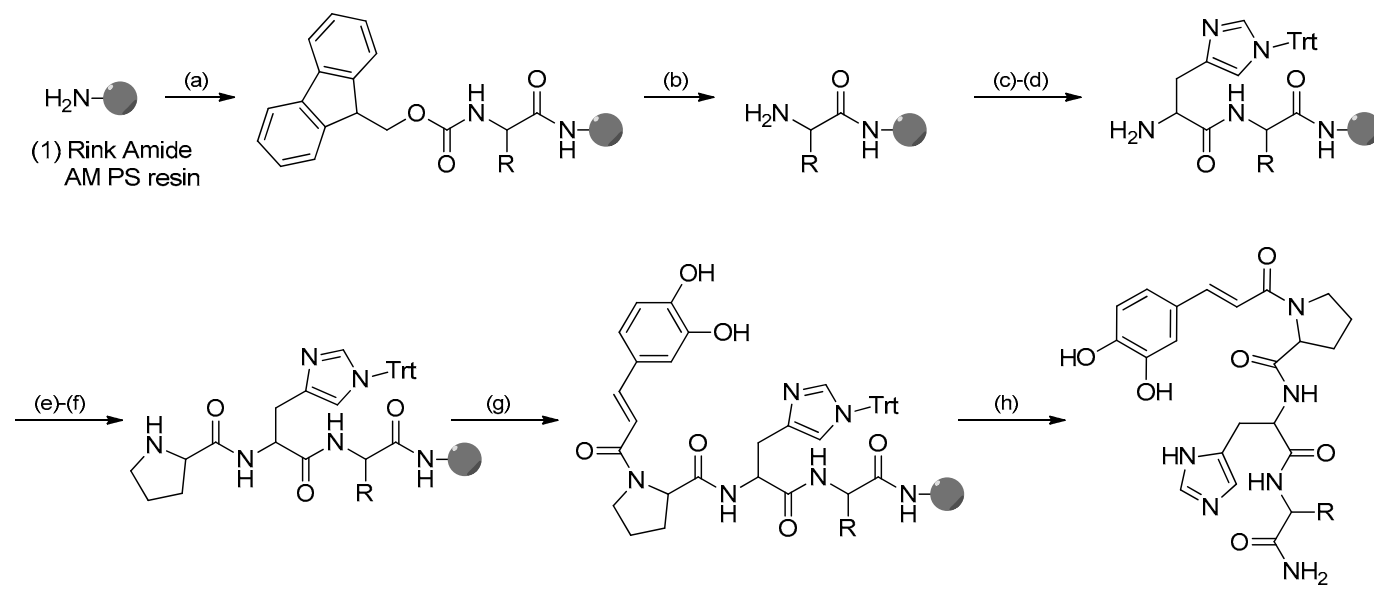

(2) CA-PHXaa

Scheme 1. Solid-phase synthesis of the CA-PHX derivatives. Reagents and conditions: (a) Fmoc-L-amino acid (3 equiv.), HBTU (3 equiv.), HOBt (3 equiv.), DIPEA (6 equiv.), DMF, 2 h; (b) 20\% piperidine/DMF (v/v), 5 and 10 min; (c) Fmoc-L-His$\mathrm{OH}$ (3 equiv.), HBTU (3 equiv.), HOBt (3 equiv.), DIPEA (6 equiv.), DMF, 2 h; (d) repeat (b); (e) Fmoc-L-Pro-OH (3 equiv.), HBTU (3 equiv.), HOBt (3 equiv.), DIPEA (6 equiv.), DMF, 2 h; (f) repeat (b); (g) CA (3 equiv.), DIC (3 equiv.), HOBt (3 equiv.), DIPEA (6 equiv.), DMF, 2 h; (h) treatment of dry resin with cleavage cocktail ( $88 \%$ TFA $/ 5 \%$ phenol $/ 5 \%$ water $/ 2 \%$ TIPS) for $1 \mathrm{~h}$ and precipitation using diethyl ether. R: side chain of amino acid (serine, arginine, aspartic acid, glycine, asparagine, phenylalanine, lysine, glutamic acid, alanine and glutamine).

Table 1. Yields and purities of the representative tripeptides $\left(\mathrm{PHX}-\mathrm{NH}_{2}\right)$ synthesized using Rink amide MBHA resin and Rink amide AM PS resin.

\begin{tabular}{ccccc}
\hline \multirow{2}{*}{ Tripeptide } & \multicolumn{2}{c}{ Rink Amide MBHA Resin } & \multicolumn{2}{c}{ Rink Amide AM PS Resin } \\
\cline { 2 - 5 } & Yield (\%) & Purity (\%) & Yield (\%) & Purity (\%) \\
\hline PHS-NH $_{2}$ & 49.4 & 89.7 & 89.6 & 96.2 \\
PHA-NH $_{2}$ & 57.5 & 94.0 & 82.2 & 97.4 \\
PHN-NH $_{2}$ & 49.5 & 90.0 & $>99$ & 95.4 \\
PHD-NH & 47.8 & 89.5 & 97.3 & 93.7 \\
\hline
\end{tabular}

Thus, several CA-PHX-NH 2 derivatives were synthesized on Rink amide AM PS resin and obtained as white powders upon precipitation of the cleaved product using cold diethyl ether with crude purities in the range of 72-79\%, as confirmed by ESI-MS (Table 2). Finally, the CA-PH-NH $\mathrm{N}_{2}$ and CA-PHX-NH 2 derivatives were obtained with $>96 \%$ purity using preparative HPLC (Supplementary Figures S1-S11). The purified products were used for further investigation of their antioxidant activity. 
Table 2. Purity and ESI-MS results of CA-PHX-NH2.

\begin{tabular}{|c|c|c|c|c|}
\hline \multirow[b]{2}{*}{ CA-PHX-NH } & \multirow{2}{*}{$\begin{array}{c}\text { Crude Purity } \\
(\%)\end{array}$} & \multirow{2}{*}{$\begin{array}{l}\text { Refinement } \\
\text { Purity (\%) }\end{array}$} & \multicolumn{2}{|c|}{ ESI-MS } \\
\hline & & & $\begin{array}{c}\text { Calculated } \\
{[\mathrm{M}+\mathrm{H}]^{+}}\end{array}$ & $\begin{array}{c}\text { Found } \\
{[\mathbf{M}+\mathbf{H}]^{+}}\end{array}$ \\
\hline CA-PH-NH ${ }_{2}$ & 74.6 & 98.2 & 414.43 & 414.02 \\
\hline CA-PHS-NH 2 & 77.6 & 98.5 & 501.49 & 501.07 \\
\hline CA-PHR-NH 2 & 76.3 & 97.4 & 570.60 & 570.00 \\
\hline CA-PHD-NH 2 & 72.6 & 99.5 & 529.5 & 529.04 \\
\hline CA-PHG-NH 2 & 73.4 & 97.1 & 471.46 & 471.03 \\
\hline CA-PHN-NH 2 & 76.9 & 98.7 & 528.51 & 528.09 \\
\hline CA-PHF-NH 2 & 79.9 & 99.2 & 561.59 & 561.02 \\
\hline CA-PHK-NH 2 & 79.7 & 98.5 & 542.58 & 542.14 \\
\hline CA-PHE-NH 2 & 75.9 & 97.7 & 543.53 & 543.04 \\
\hline CA-PHA-NH ${ }_{2}$ & 73.4 & 98.1 & 485.49 & 485.07 \\
\hline CA-PHQ-NH 2 & 75.1 & 96.1 & 542.54 & 541.96 \\
\hline
\end{tabular}

\subsection{Antioxidative Activities of the $\mathrm{CA}-\mathrm{PHX}-\mathrm{NH}_{2}$ Derivatives}

\subsubsection{2,2-Diphenyl-1-picrylhydrazyl (DPPH) Test}

The free-radical scavenging activity (RSA) of the purified CA-PHX- $\mathrm{NH}_{2}$ derivatives was evaluated using a DPPH radical scavenging test. When the CA-PHX-NH $\mathrm{N}_{2}$ derivatives were in their radical form after donating a hydrogen atom to DPPH, the color of the DPPH solution in methanol $(\mathrm{MeOH})$ changed from purple to yellow (Supplementary Figure S12), and the absorbance observed at $516 \mathrm{~nm}$ decreased. Figure 2 shows the observed RSA (\%) values, which were calculated using the following equation:

$$
\text { RSA }(\%)=(1-\text { Abs. of sample } / \text { Abs. of control }) \times 100 \text {. }
$$

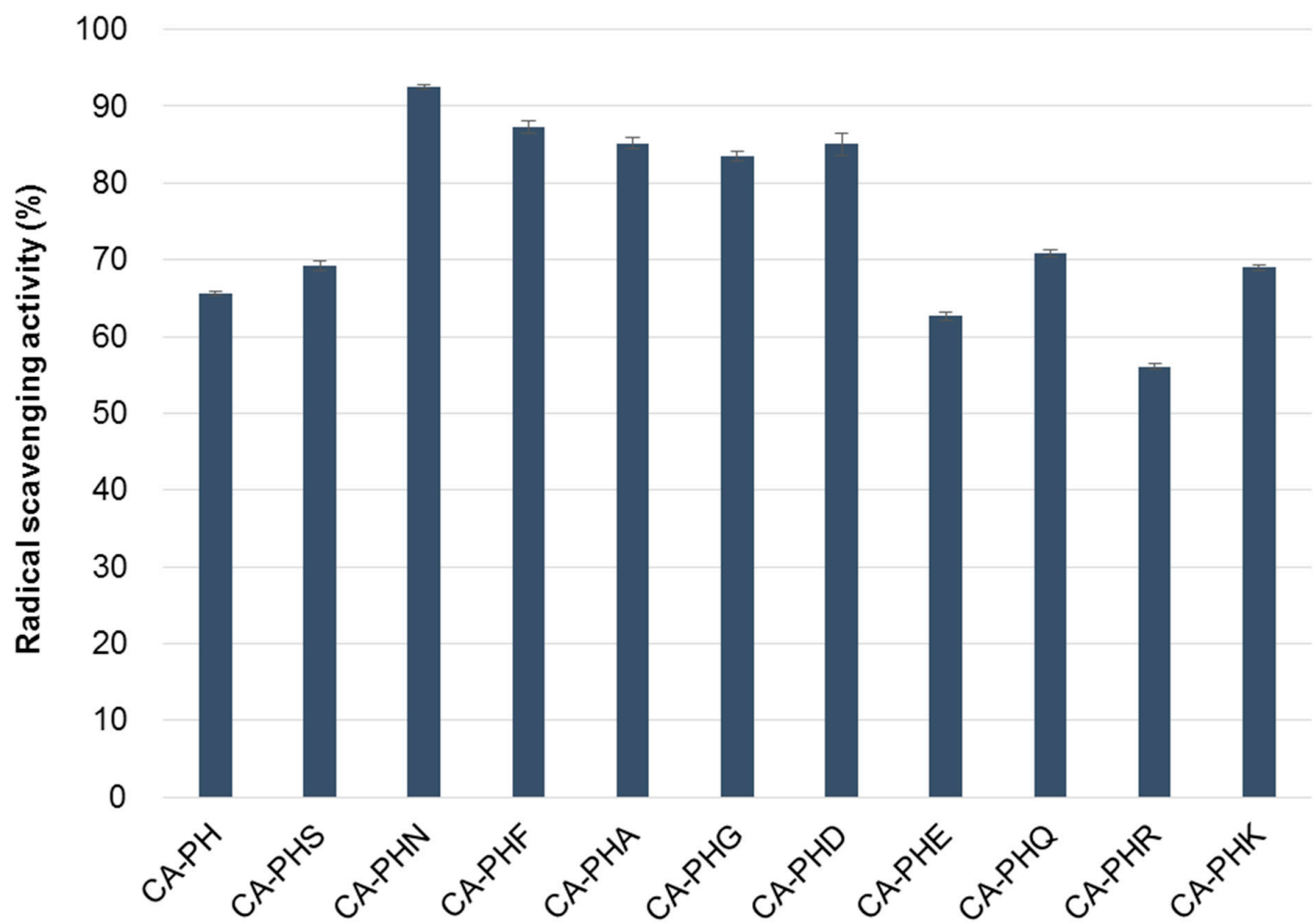

Figure 2. DPPH radical scavenging activity of the CA-PHX- $\mathrm{NH}_{2}$ derivatives. Each experiment was performed in triplicate. Results are presented as mean \pm standard error. 
Some of the CA-PHX-NH ${ }_{2}$ derivatives exhibited higher RSA (\%) values than CA-PH$\mathrm{NH}_{2}$, in the following order: CA-PHN-NH ${ }_{2}(92.5)>$ CA-PHF-NH 2 (87.2) $\approx$ CA-PHA-NH $(85.2) \approx \mathrm{CA}-\mathrm{PHD}-\mathrm{NH}_{2}(85.1) \approx \mathrm{CA}-\mathrm{PHG}-\mathrm{NH}_{2}(83.5)>$ CA-PHQ-NH 2 (70.8) $\approx$ CA-PHS$\mathrm{NH}_{2}(69.2) \approx \mathrm{CA}-\mathrm{PHK}-\mathrm{NH}_{2}(69.0)>\mathrm{CA}-\mathrm{PH}-\mathrm{NH}_{2}(65.5)>$ CA-PHE-NH ${ }_{2}(62.7)>$ CA$\mathrm{PHR}-\mathrm{NH}_{2}$ (56.1). The various side chains of the amino acids influenced the coordination with catechol moiety in CA-PHX- $\mathrm{NH}_{2}$, which resulted in different antioxidant activities. CA-PHN-NH$H_{2}$ exhibited the highest RSA (\%) value when compared to CA-PHX-NH $\mathrm{N}_{2}$ and CA-PH-NH ${ }_{2}$. The addition of asparagine further stabilized the oxidation state of CA-PH$\mathrm{NH}_{2}$. We presume that the antioxidant activity was improved by the amide side chain of asparagine coordinating precisely with the redox-active catechol moiety in CA-PHN-NH 2 . Further research would clarify the structure of the oxidation state of CA-PHN-NH 2 .

\subsubsection{Lipid Peroxidation (LPO) Test}

The antioxidant activity was also measured using a lipid peroxidation (LPO) inhibition assay using Tween 20-emulsified linoleic acid (Supplementary Figure S13). The percentage of lipid peroxidation inhibition (\%Pi) was calculated using the following equation:

$$
\% \mathrm{Pi}=(1-\text { Abs. of sample/Abs. of control }) \times 100 \text {. }
$$

The $\% \mathrm{Pi}$ values observed for the CA-PHX- $\mathrm{NH}_{2}$ derivatives and $\mathrm{CA}-\mathrm{PH}-\mathrm{NH}_{2}$ decreased in the following order after $24 \mathrm{~h}$ : CA-PHR-NH ${ }_{2}$ (86.2) > CA-PHK-NH $\mathrm{N}_{2}(86.1)>$ CA-PHS-NH ${ }_{2}$ (85.5) $>$ CA-PHF-NH ${ }_{2}$ (85.1) $>$ CA-PHE-NH ${ }_{2}$ (85.0) $>$ CA-PHG-NH ${ }_{2}(84.7)>$ CA-PHQ-NH ${ }_{2}(84.0)>$ CA-PHA-NH ${ }_{2}$ (80.2) $>$ CA-PH-NH 2 (78.6) $>$ CA-PHN-NH ${ }_{2}(74.9)$ $>$ CA-PHD-NH $\mathrm{N}_{2}$ (70.7). Figure 3 shows that most of the CA-PHX-NH $\mathrm{N}_{2}$ derivatives were superior to CA-PH-NH ${ }_{2}$ in the LPO inhibition assay. Hydrophilic DPPH and hydrophobic LPO tests showed different patterns for the antioxidant activity among the caffeoyl peptide derivatives studied. For example, $\mathrm{CA}-\mathrm{PHN}-\mathrm{NH}_{2}$ showed the highest antioxidant activity in the DPPH test but had a lower activity than CA-PH- $\mathrm{NH}_{2}$ in the LPO inhibition assay. These differences can be attributed to the different solubilities of the derivatives in the working solutions used.

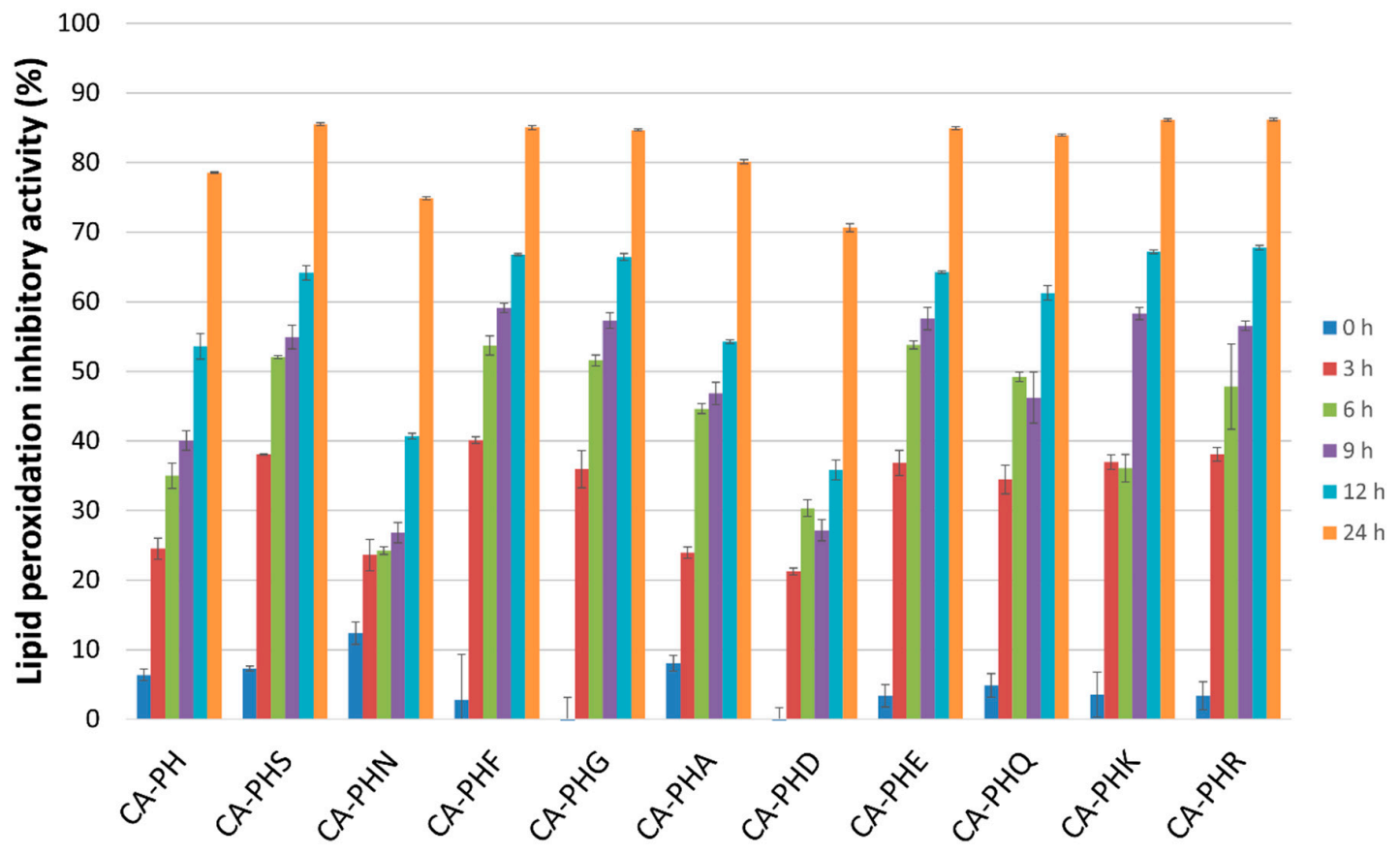

Figure 3. Antioxidant activity of the CA-PHX-NH 2 derivatives under lipid peroxidation conditions. Each experiment was performed in triplicate. Results are presented as mean \pm standard error. 


\subsection{Cytotoxicity of the $\mathrm{CA}-\mathrm{PHX}-\mathrm{NH}_{2}$ Derivatives}

The MTT assay data exhibited no significant cytotoxicity for the CA-PHX- $\mathrm{NH}_{2}$ derivatives at low concentration $(1 \mu \mathrm{M})$. Even at concentrations as high as $100 \mu \mathrm{M}$, most of the CA-PHX-NH $\mathrm{N}_{2}$ derivatives were not cytotoxic, while some of the compounds, such as CAPHA-NH ${ }_{2}$, CA-PHR-NH ${ }_{2}$ and CA-PHK-NH ${ }_{2}$, showed cell viabilities of $<80 \%$. In the case of CA-PH-NH ${ }_{2}, \mathrm{CA}-\mathrm{PHS}-\mathrm{NH}_{2}, \mathrm{CA}-\mathrm{PHN}-\mathrm{NH}_{2}$ and CA-PHQ-NH ${ }_{2}$, cell viabilities exceeded $100 \%$. We presume that those CA derivatives reduced the oxidative stress of the cells and promoted cell proliferation, overcoming cytotoxicity (Figure 4). Thus, CA-PHX-NH derivatives exhibiting low cytotoxicity have potential use as cosmetic ingredients.

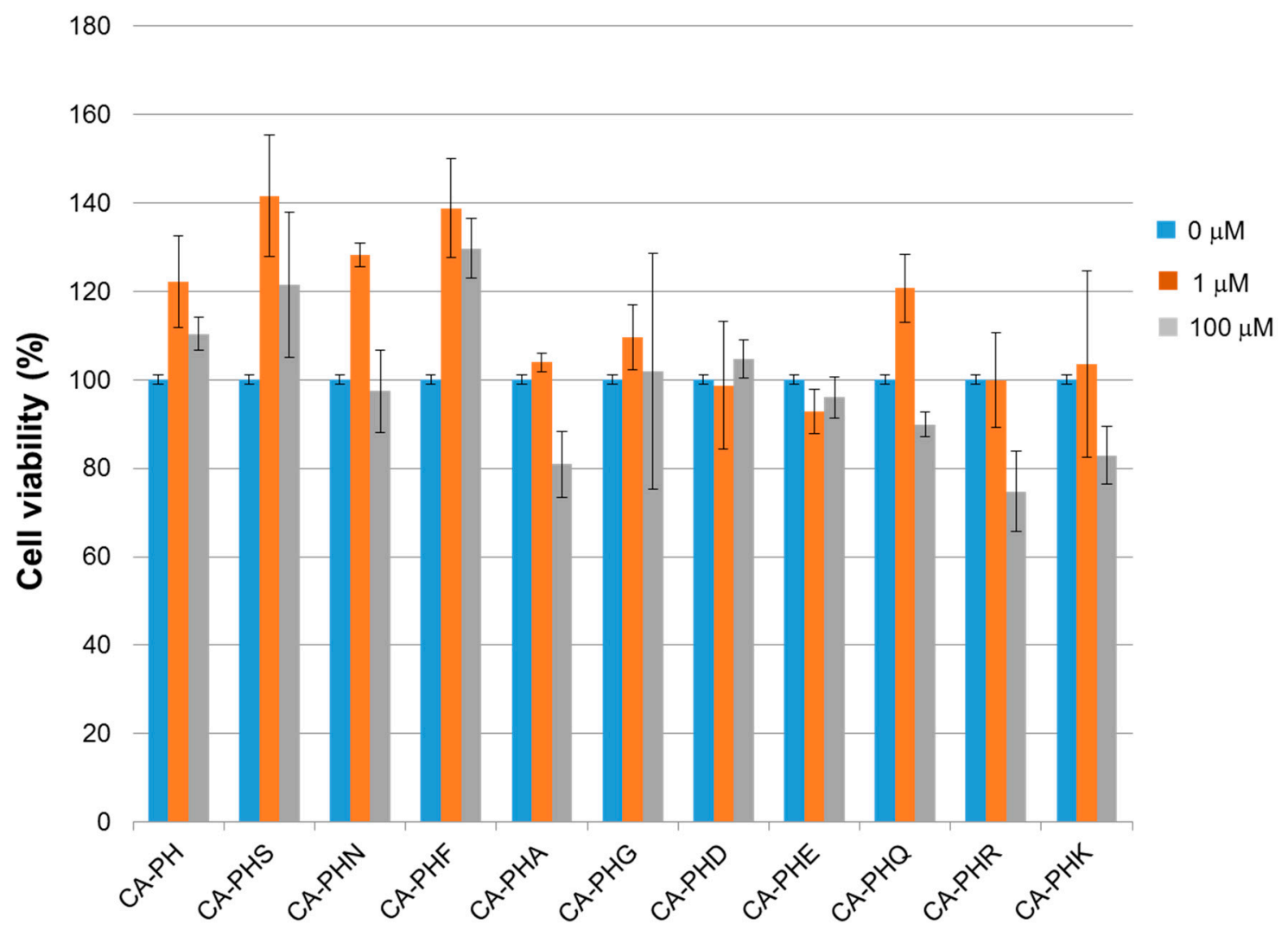

Figure 4. Cytotoxicity of the CA-PHX- $\mathrm{NH}_{2}$ derivatives measured using MTT assay. Each experiment was performed in triplicate. Results are presented as mean \pm standard error.

\subsection{Stability Evaluation Using ${ }^{1} H-N M R$ Spectroscopy}

${ }^{1} \mathrm{H}-\mathrm{NMR}$ spectroscopy was used to evaluate the long-term structural stability of CAPHN- $-\mathrm{NH}_{2}$. The changes in the molar ratio of s-cis Pro, which demonstrates the stability of CA-PHN-NH $\mathrm{N}_{2}$, were monitored upon storage at $25{ }^{\circ} \mathrm{C}$ under dark conditions over 3 months. The ratio of the s-cis form remained $>93 \%$ for 3 months (Table 3, Supplementary Figure S14). The ${ }^{1} \mathrm{H}-\mathrm{NMR}$ spectra show that $\mathrm{CA}-\mathrm{PHN}-\mathrm{NH}_{2}$ exhibited limited transition between the cis and trans conformations over 3 months, which is critical for maintaining its high antioxidation activity [26]. Therefore, CA-PHN- $\mathrm{NH}_{2}$ will likely maintain its antioxidant activity in hydrophilic solutions upon long-term storage. 
Table 3. Ratio of the s-cis form of CA-PHN-NH 2 .

\begin{tabular}{cccc}
\hline CA-PHN-NH & \multicolumn{3}{c}{$\begin{array}{c}\text { Relative Integral Intensity (\%) } \\
\text { (Ratio of } s \text {-cis Form) }\end{array}$} \\
\hline CH= Proton & His C $^{\varepsilon 1}$-H Proton & Average \\
\hline 0 h & 94.38 & 94.61 & 94.50 \\
1 week & 93.84 & 94.01 & 93.93 \\
1 month & 93.40 & 94.22 & 93.81 \\
2 months & 95.04 & 93.82 & 94.43 \\
3 months & 93.69 & 95.53 & 94.61 \\
\hline
\end{tabular}

\section{Materials and Methods}

\subsection{Materials}

Triisopropylsilane (TIPS), caffeic acid (CA), 2,2-diphenyl-1-picrylhydrazyl (DPPH), linoleic acid, thiazolyl blue tetrazolium bromide (MTT), ammonium thiocyanate, Tween 20, sodium phosphate dibasic dodecahydrate, sodium phosphate monobasic dihydrate, ethanol (EtOH) and iron(II) chloride tetrahydrate $\left(\mathrm{FeCl}_{2} \cdot 4 \mathrm{H}_{2} \mathrm{O}\right)$ were purchased from Sigma-Aldrich (St. Louis, MO, USA). Functionalized resins, 9-fluorenylmethyloxycarbonyl (Fmoc)-Rink amide linker, Fmoc amino acids, $N, N^{\prime}$-diisopropylcarbodiimde (DIC), $N, N$, $N^{\prime}, N^{\prime}$-tetramethyl-O-(1H-benzotriazol-1-yl)uranium hexafluorophosphate (HBTU), 1 hydroxybenzotriazole $(\mathrm{HOBt})$ and filtered reaction tubes (Libra tube ${ }^{\circledR}$ ) were purchased from BeadTech Inc. (Ansan, Korea). Acetonitrile (ACN), dichloromethane (DCM), $N, N$ diisopropylethylamine (DIPEA), methanol (MeOH), N,N-dimethylformamide (DMF), dimethylsulfoxide (DMSO), acetic anhydride, hydrochloric acid $(\mathrm{HCl})$, piperidine, trifluoroacetic acid (TFA) and phenol were purchased from Daejung Chemical \& Metals Co. Ltd. (Siheung, Korea). NIH 3T3 mouse fibroblasts were purchased from Korea Cell Line Bank (Seoul, Korea) and cultured in 10\% $(v / v)$ fetal bovine serum (FBS) and 1\% $(v / v)$ penicillin streptomycin in RPMI 1640 media (Biowest, Nuaillé, France) at $37^{\circ} \mathrm{C}$ in a humidified $5 \% \mathrm{CO}_{2}$ atmosphere. Trypsin-ethylenediaminetetraacetic acid (EDTA) in Hanks' balanced salt solution (HBSS) was purchased from Biowest (Nuaillé, France).

\subsection{Solid-Phase Synthesis of CA-PHX-NH2}

Prolyl-histidyl-Xaa- $\mathrm{NH}_{2}$ was synthesized on two types of resin using $\mathrm{Fmoc} / \mathrm{t}$-Bu chemistry. The tripeptides were synthesized on a Rink amide resin (300 mg) by repeating the coupling and deprotection steps: (a) in the coupling step, the resins were treated with a solution of Fmoc-amino acid (3.0 equiv.), HBTU (3.0 equiv.), HOBt (3.0 equiv.) and DIPEA (6.0 equiv.) in DMF (10 mL) for $2 \mathrm{~h}$; (b) in the deprotection step, each resin was treated twice with $20 \%$ piperidine/DMF $(v / v)$ solution $(2 \times 10 \mathrm{~mL})$ for 5 and $10 \mathrm{~min}$. The resins were washed with DMF, DCM and $\mathrm{MeOH}$ three times after each coupling and deprotection step. The completion of each amino acid coupling reaction used in the synthesis was confirmed using Kaiser's ninhydrin test.

The CA (3.0 equiv.) was dissolved in DMF $(3 \mathrm{~mL})$ in a glass vial. To this solution, HOBt (3.0 equiv.) and DIC (3.0 equiv.) were added, and the resulting mixture was stirred at room temperature for 30 min under dark conditions. The mixture was added to a reaction tube containing Pro-His- $\mathrm{Xaa}^{-\mathrm{NH}_{2}}$ and DIPEA (6.0 equiv.) and incubated in a multirotator for $1 \mathrm{~h}$ at room temperature. The resin was washed three times with DMF, $\mathrm{DCM}$ and $\mathrm{MeOH}$. The resin was treated with a cleavage cocktail comprising trifluoroacetic acid/phenol/triisopropylsilane/water (88:5:5:2, $/ / v / v / v ; 3 \mathrm{~mL})$ for $2 \mathrm{~h}$. After removal of the resin, the resulting solution was precipitated upon the addition of diethyl ether. The supernatant was decanted after centrifugation, and the remaining pellet was washed three times with diethyl ether via centrifugation and dried in vacuo. The purities of the peptides and CA-PHX-NH $\mathrm{N}_{2}$ were analyzed using HPLC under the following conditions: gradient elution with A ( $0.1 \%$ TFA in water) and B ( $0.1 \%$ TFA in acetonitrile) from $10 \%$ to $90 \%$ B over $41 \mathrm{~min}$; flow rate of $1.0 \mathrm{~mL} / \mathrm{min}$; UV detection at 230 and $214 \mathrm{~nm}$; column temperature of $35.0{ }^{\circ} \mathrm{C}$. 


\subsection{Antioxidant Activities of $\mathrm{CA}-\mathrm{PHX}-\mathrm{NH}_{2}$}

\subsubsection{2,2-Diphenyl-1-picrylhydrazyl (DPPH) Test}

A DPPH/MeOH solution $(0.1 \mathrm{mM}, 1.48 \mathrm{~mL})$ was placed in a microtube and treated with a solution of the CA-PHX- $\mathrm{NH}_{2}$ derivative in $\mathrm{MeOH}(50 \mu \mathrm{M}, 0.2 \mathrm{~mL})$ for $10 \mathrm{~min}$. The absorbance of the DPPH mixture was measured at $516 \mathrm{~nm}$ using a UV/Vis spectrophotometer [22].

\subsubsection{LPO Test}

A linoleic acid emulsion ( $25 \mathrm{mM})$ was prepared by mixing linoleic acid $(142 \mathrm{mg})$, Tween $20(142 \mathrm{mg})$ and sodium phosphate buffer $(0.1 \mathrm{M}, \mathrm{pH}$ 7.0, $50 \mathrm{~mL})$. As antioxidants of the linoleic acid emulsion, solutions of the CA-PHX-NH $\mathrm{NH}_{2}$ derivatives $(9,45$ and $90 \mu \mathrm{M}$ and $0.5 \mathrm{~mL})$ were prepared in a mixture of water $(0.5 \mathrm{~mL})$ and sodium phosphate buffer $(0.1 \mathrm{M}$, $2.0 \mathrm{~mL}$ ) in separate vials for the LPO test. Each mixture was kept at $50{ }^{\circ} \mathrm{C}$ under dark conditions for $24 \mathrm{~h}[28,29]$. Each mixture $(25 \mu \mathrm{L})$ was mixed with $75 \% \mathrm{EtOH}(1.175 \mathrm{~mL})$, $\mathrm{FeCl}_{2} \cdot 4 \mathrm{H}_{2} \mathrm{O}$ in $3.5 \%$ hydrochloric acid $(\mathrm{HCl})(20 \mathrm{mM}, 25 \mu \mathrm{L})$ and $25 \mu \mathrm{L}$ of $30 \% \mathrm{NH}_{4} \mathrm{SCN}$ for $3 \mathrm{~min}$. The absorbance of the mixtures at $500 \mathrm{~nm}$ was measured using a UV/Vis spectrophotometer.

\subsection{Cytotoxicity Assay for CA-PHX-NH}

NIH 3 T3 cells were seeded $(100,000$ cells $/ \mathrm{mL}, 200 \mu \mathrm{L})$ in a 96-well plate and incubated for 1 day. Solutions of each CA-PHX-NH ${ }_{2}$ derivative in RPMI 1640 media $(1,10,50$ and $100 \mu \mathrm{M})$ were prepared. The cell culture medium in each well was carefully aspirated, and the cells were treated with the CA-PHX-NH After removal of the solution, the cells were incubated in the presence of MTT solution $(200 \mu \mathrm{L})$ for $3 \mathrm{~h}$. After incubation, the MTT solution was discarded and DMSO was added to dissolve the formazan produced by the living cells. The mixtures in the 96-well plate were shaken in a shaking incubator for $20 \mathrm{~min}$. The absorbance of the dissolved formazan was measured at a wavelength of $590 \mathrm{~nm}$ using a microplate reader. The percentage of cell viability was calculated by comparison with the number of standard cells which were not treated with the solutions of CA derivatives.

\subsection{Long-Term Stability Test Using ${ }^{1} H$-NMR Spectroscopy}

The sample of CA-PHN-NH${ }_{2}$ for ${ }^{1} \mathrm{H}-\mathrm{NMR}$ spectroscopy was prepared by dissolving $10 \mathrm{mg}$ of compound $( \pm 0.01 \mathrm{mg})$ in $1 \mathrm{~mL}$ of methanol- $\mathrm{d}_{6}(\mathrm{MeOD})$. The resulting solution was transferred to a $5 \mathrm{~mm}$ standard NMR tube. The ${ }^{1} \mathrm{H}-\mathrm{NMR}$ spectra were obtained on a Bruker AVANCE III-HD500 spectrometer operated at 500 MHz. Tetramethylsilane (TMS) was used as an internal standard for the analysis of the chemical shifts.

\section{Conclusions}

A library of caffeoyl tripeptides (CA-PHX-NH 2 ) was synthesized, and their antioxidant activities were evaluated to develop new CA-peptide derivatives with enhanced antioxidant capacity compared to CA-PH- $\mathrm{NH}_{2}$. The DPPH assay showed that CA-PHN-NH exhibited the highest free RSA (92.5\%), compared to CA-PHX-NH ${ }_{2}$ and CA-PH-NH $\mathrm{N}_{2}$. None of the CA derivatives exhibited significant cytotoxicity at concentrations up to $100 \mu \mathrm{M}$. ${ }^{1} \mathrm{H}-\mathrm{NMR}$ spectroscopy showed that CA-PHN-NH $\mathrm{N}_{2}$ maintained its structural integrity for up to 3 months. Therefore, CA-PHN-NH ${ }_{2}$ is expected to be used as a raw material for pharmaceutical or cosmetic ingredients because of its superior antioxidant ability and long-term stability.

Supplementary Materials: Supplementary materials can be found at https://www.mdpi.com/ article/10.3390/ijms22126301/s1. Figure S1. HPLC chromatograms of (a) crude CA-PH-NH ${ }_{2}$, (b) purified CA-PH-NH 2 , and (c) ESI-MS data of CA-PH-NH $\mathrm{N}_{2}$, Figure S2. HPLC chromatograms of (a) crude CA-PHS-NH ${ }_{2}$, (b) purified CA-PHS-NH ${ }_{2}$, and (c) ESI-MS data of CA-PHS-NH ${ }_{2}$, Figure S3. HPLC chromatograms of (a) crude CA-PHR-NH $\mathrm{N}_{2}$, (b) purified CA-PHR-NH $\mathrm{N}_{2}$, and (c) ESI-MS data 
of CA-PHR-NH ${ }_{2}$, Figure S4. HPLC chromatograms of (a) crude CA-PHD-NH $\mathrm{N}_{2}$, (b) purified CAPHD-NH ${ }_{2}$, and (c) ESI-MS data of CA-PHD-NH ${ }_{2}$, Figure S5. HPLC chromatograms of (a) crude CA-PHG-NH ${ }_{2}$, (b) purified CA-PHG-NH ${ }_{2}$, and (c) ESI-MS data of CA-PHG-NH ${ }_{2}$, Figure S6. HPLC chromatograms of (a) crude CA-PHN-NH ${ }_{2}$, (b) purified CA-PHN-NH ${ }_{2}$, and (c) ESI-MS data of CA$\mathrm{PHN}_{-} \mathrm{NH}_{2}$, Figure S7. HPLC chromatograms of (a) crude CA-PHF-NH $\mathrm{N}_{2}$, (b) purified CA-PHF-NH and (c) ESI-MS of CA-PHF-NH ${ }_{2}$, Figure S8. HPLC chromatograms of (a) crude CA-PHK-NH ${ }_{2}$, (b) purified CA-PHK-NH $\mathrm{N}_{2}$, and (c) ESI-MS of CA-PHK-NH ${ }_{2}$, Figure S9. HPLC chromatograms of (a) crude CA-PHE-NH $\mathrm{N}_{2}$, (b) purified CA-PHE-NH $\mathrm{N}_{2}$, and (c) ESI-MS data of CA-PHE-NH $\mathrm{N}_{2}$, Figure S10. HPLC chromatograms of (a) crude CA-PHA-NH $\mathrm{NH}_{2}$, (b) purified CA-PHA-NH $\mathrm{N}_{2}$, and (c) ESI-MS data of CA-PHA-NH ${ }_{2}$, Figure S11. HPLC chromatograms of (a) crude CA-PHQ-NH 2 , (b) purified CA-PHQ$\mathrm{NH}_{2}$, and (c) ESI-MS data of CA-PHQ-NH $\mathrm{N}_{2}$, Figure S12. Mechanism of the DPPH radical scavenging test, Figure S13. Mechanism of lipid peroxidation inhibition test, Figure S14. ${ }^{1} \mathrm{H}-\mathrm{NMR}$ spectra of CA-PHN- $\mathrm{NH}_{2}$ tripeptides for 3 months at room temperature in the dark.

Author Contributions: H.J. and Y.-E.J. designed and performed the experiments and analyzed the data. Y.-S.L. and D.-S.S. designed the experiments and analyzed the data. H.J., Y.-E.J., Y.-S.L. and D.-S.S. wrote the manuscript. J.-K.Y. and J.K. performed the experiments and analyzed the data. W.-J.C. analyzed the data and edited the manuscript. All authors have read and agreed to the published version of the manuscript.

Funding: This work was financially supported by the research fund of the Industrial Strategic Technology Development Program (10077652) of the Ministry of Trade, Industry, and Energy (MOTIE), the Korean Evaluation Institute of Industrial Technology (KEIT) and the Basic Science Research Program through the National Research Foundation of Korea (NRF-2019R1F1A1062208).

Institutional Review Board Statement: Not applicable.

Informed Consent Statement: Not applicable.

Conflicts of Interest: The authors declare no conflict of interest. The funders had no role in the design of the study; in the collection, analysis, or interpretation of data; in the writing of the manuscript; or in the decision to publish the results.

$\begin{array}{ll}\text { Abbreviations } & \\ \text { CA-PHX-NH } & \\ \text { AM PS } & \text { Caffeoyl-prolyl-histidyl-X amino acid amide } \\ \text { MBHA } & \text { Aminomethyl polystyrene } \\ \text { DPPH } & \text { 2,-2-Diphethenzhyl-1-picrylhydrazyl } \\ \text { LPO } & \text { Lipid peroxidation }\end{array}$

\section{References}

1. Apel, K.; Hirt, H. Reactive oxygen species: Metabolism, oxidative stress, and signal transduction. Annu. Rev. Plant Biol. 2004, 55, 373-399. [CrossRef] [PubMed]

2. Halliwell, B. Antioxidants in human health and disease. Annu. Rev. Nutr. 1996, 16, 33-50. [CrossRef] [PubMed]

3. Benzi, G.; Moretti, A. Are reactive oxygen species involved in Alzheimer's disease? Neurobiol. Aging 1995, 16, 661-674. [CrossRef]

4. Perry, G.; Castellani, R.J.; Hirai, K.; Smith, M.A. Reactive oxygen species mediate cellular damage in Alzheimer disease. J. Alzheimer's Dis. 1998, 1, 45-55. [CrossRef]

5. Zhao, B. Natural antioxidants protect neurons in Alzheimer's disease and Parkinson's disease. Neurochem. Res. 2009, 34, 630-638. [CrossRef]

6. Moure, A.; Cruz, J.M.; Franco, D.; Domínguez, J.M.; Sineiro, J.; Domínguez, H.; Núñez, M.J.; Parajó, J.C. Natural antioxidants from residual sources. Food Chem. 2001, 72, 145-171. [CrossRef]

7. Pokorný, J. Are natural antioxidants better-and safer-than synthetic antioxidants? Eur. J. Lipid Sci. Technol. 2007, 109, 629-642. [CrossRef]

8. Chen, Z.; Chan, P.; Kwan, K.; Zhang, A. Reassessment of the antioxidant activity of conjugated linoleic acids. J. Am. Oil Chem. Soc. 1997, 74, 749-753. [CrossRef]

9. Shahidi, F. Antioxidants in food and food antioxidants. Food/Nahrung 2000, 44, 158-163. [CrossRef]

10. Guan, Y.; Chu, Q.; Fu, L.; Ye, J. Determination of antioxidants in cosmetics by micellar electrokinetic capillary chromatography with electrochemical detection. J. Chromatogr. A 2005, 1074, 201-204. [CrossRef] 
11. Rayner, B.S.; Duong, T.H.; Myers, S.J.; Witting, P.K. Protective effect of a synthetic anti-oxidant on neuronal cell apoptosis resulting from experimental hypoxia re-oxygenation injury. J. Neurochem. 2006, 97, 211-221. [CrossRef] [PubMed]

12. Branen, A. Toxicology and biochemistry of butylated hydroxyanisole and butylated hydroxytoluene. J. Am. Oil Chem. Soc. 1975, 52, 59-63. [CrossRef] [PubMed]

13. Wright, J.S.; Johnson, E.R.; DiLabio, G.A. Predicting the activity of phenolic antioxidants: Theoretical method, analysis of substituent effects, and application to major families of antioxidants. J. Am. Chem. Soc. 2001, 123, 1173-1183. [CrossRef] [PubMed]

14. Graf, E. Antioxidant potential of ferulic acid. Free Radic. Biol. Med. 1992, 13, 435-448. [CrossRef]

15. Son, S.; Lewis, B.A. Free radical scavenging and antioxidative activity of caffeic acid amide and ester analogues: Structure-activity relationship. J. Agric. Food Chem. 2002, 50, 468-472. [CrossRef] [PubMed]

16. Cheng, Z.; Ren, J.; Li, Y.; Chang, W.; Chen, Z. Study on the multiple mechanisms underlying the reaction between hydroxyl radical and phenolic compounds by qualitative structure and activity relationship. Bioorganic Med. Chem. 2002, 10, 4067-4073. [CrossRef]

17. Shahidi, F.; Janitha, P.; Wanasundara, P. Phenolic antioxidants. Crit. Rev. Sci. Nutr. 1992, 32, 67-103. [CrossRef]

18. Doiron, J.A.; Métayer, B.; Richard, R.R.; Desjardins, D.; Boudreau, L.H.; Levesque, N.A.; Jean-François, J.; Poirier, S.J.; Surette, M.E.; Touaibia, M. Clicked cinnamic/caffeic esters and amides as radical scavengers and 5-lipoxygenase inhibitors. Int. J. Med. Chem. 2014, 2014. [CrossRef] [PubMed]

19. Marinova, E.; Georgiev, L.; Totseva, I.; Seizova, K.; Milkova, T. Antioxidant activity and mechanism of action of some synthesised phenolic acid amides of aromatic amines. Czech J. Food Sci. 2013, 31, 5-13. [CrossRef]

20. Rajan, P.; Vedernikova, I.; Cos, P.; Berghe, D.V.; Augustyns, K.; Haemers, A. Synthesis and evaluation of caffeic acid amides as antioxidants. Bioorganic Med. Chem. Lett. 2001, 11, 215-217. [CrossRef]

21. Kwak, S.Y.; Seo, H.S.; Lee, Y.S. Synergistic antioxidative activities of hydroxycinnamoyl-peptides. J. Pept. Sci. Off. Publ. Eur. Pept. Soc. 2009, 15, 634-641. [CrossRef] [PubMed]

22. Pekkarinen, S.S.; Stöckmann, H.; Schwarz, K.; Heinonen, I.M.; Hopia, A.I. Antioxidant activity and partitioning of phenolic acids in bulk and emulsified methyl linoleate. J. Agric. Food Chem. 1999, 47, 3036-3043. [CrossRef] [PubMed]

23. Seo, H.-S.; Kwak, S.-Y.; Lee, Y.-S. Antioxidative activities of histidine containing caffeic acid-dipeptides. Bioorganic Med. Chem. Lett. 2010, 20, 4266-4272. [CrossRef] [PubMed]

24. Spasova, M.; Kortenska-Kancheva, V.; Totseva, I.; Ivanova, G.; Georgiev, L.; Milkova, T. Synthesis of cinnamoyl and hydroxycinnamoyl amino acid conjugates and evaluation of their antioxidant activity. J. Pept. Sci. Off. Publ. Eur. Pept. Soc. 2006, 12, 369-375. [CrossRef] [PubMed]

25. Stankova, I.; Chuchkov, K.; Shishkov, S.; Kostova, K.; Mukova, L.; Galabov, A.S. Synthesis, antioxidative and antiviral activity of hydroxycinnamic acid amides of thiazole containing amino acid. Amino Acids 2009, 37, 383-388. [CrossRef] [PubMed]

26. Kwak, S.-Y.; Lee, H.J.; Yang, J.-K.; Lee, E.J.; Seo, M.; Lee, Y.-S. Antioxidant activity of caffeoyl-prolyl-histidine amide and its effects on PDGF-induced proliferation of vascular smooth muscle cells. Amino Acids 2014, 46, 2777-2785. [CrossRef]

27. Matsueda, G.R.; Stewart, J.M. A p-methylbenzhydrylamine resin for improved solid-phase synthesis of peptide amides. Peptides 1981, 2, 45-50. [CrossRef]

28. Mitsuda, H. Antioxidative action of indole compounds during the autoxidation of linoleic acid. Eiyo Shokuryo 1966, 19, $210-221$. [CrossRef]

29. Chen, H.-M.; Muramoto, K.; Yamauchi, F. Structural analysis of antioxidative peptides from Soybean. beta.-Conglycinin. J. Agric. Food Chem. 1995, 43, 574-578. [CrossRef] 